\title{
Using Robust-DEA optimization approach to analyze performance and efficiency of a mine in north of Iran
}

\author{
Masoud Rabbani ${ }^{\mathrm{a}^{*}}$, Hamed Farrokhi-Asl ${ }^{\mathrm{b}}$ and Neda Manavizadeh ${ }^{\mathrm{c}}$
}

${ }^{a}$ School of Industrial Engineering, College of Engineering, University of Tehran, Tehran, Iran

${ }^{b}$ School of Industrial Engineering, Iran University of Science \& Technology, Tehran, Iran

${ }^{c}$ Department of Industrial Engineering, KHATAM University, Tehran, Iran

\section{H R O N I C L E}

Article history:

Received: October 1, 2016

Received in revised format: No-

vember 16, 2016

Accepted: November 24, 2016

Available online:

November 27, 2016

Keywords:

Data envelopment analysis

Robust DEA

Safety and economic factors

Mine performance

\section{A B S T R A C T}

Performance of mines can be affected by different factors such as safety and economic factors. This study aims to analyze the influence of safety and economic factors on mines' performance. To this purpose, a framework is proposed based on a Data Envelopment Analysis (DEA), Robust Data Envelopment Analysis (RDEA) and common weight Robust Data Envelopment Analysis (CWRDEA) to determine the factors affecting on performance of mines. In this study, for the first time, integrated economic and safety factors are considered for evaluation of mines performance. To analyze safety and economic factors, this research gathers real data from a mine with 56 sites in south of Iran. Based on different DEA models, different sites become the best site among other sites, but RDEA is much closer to real situation than basic DEA and CWRDEA is the most efficient approach in real situation.

\section{Introduction}

Statistics reveal that out of 7 billion people in the world, 3 billion have occupations. According to the International Labor Organization (ILO), 120 million accidents take place each year in work environments, 210 thousands of which are fatal. Consequences of diseases and work-related injuries are also points of interest, as they are responsible for financial loss as much as $4 \%$ of the Global gross domestic product. The researches based on the National institute for Occupational Safety and Health (NIOSHA) show that approximately 5400 deaths occur each year due to occupational hazards, most of which are related to mining industries (Pham et al., 2013). According to statistics, in 2013 more than 70 million people live in Iran and 9000 worked in mining industries. In general, there are 5445 mines in Iran, and their total production adds up to more than 3 billion dollars, which show how important mining industries are in Iran's economy. Statistics show that 1779 people or $1.87 \%$ of all the workers in this industry were injured in Iranian mines in 2013 (Ghaffari, 2013). In 2013, 4.69\% of all work-related accidents happened in the mining industries.

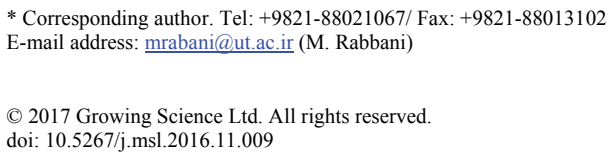


The purpose of mining safety is to prevent damages to the workers and the mine. According to Statistical center of Iran (SCI), most of the accidents happening in occupational environments include but not limited to: downfall, collision, falling debris and being trapped. These accidents mostly happen in mines and they may lead to injury or even death. Mine workers are in danger of many things such as fire, electrocution, chemical poisoning, etc. Therefore, working in a mine can actually be very dangerous. According to the ministry of cooperative labor and social welfare of Iran, Fig. 1 illustrates all kinds of work related injuries and we can see that most of them are cuts, bruises and foreign objects entering the eye, all of which are common in mining accidents.

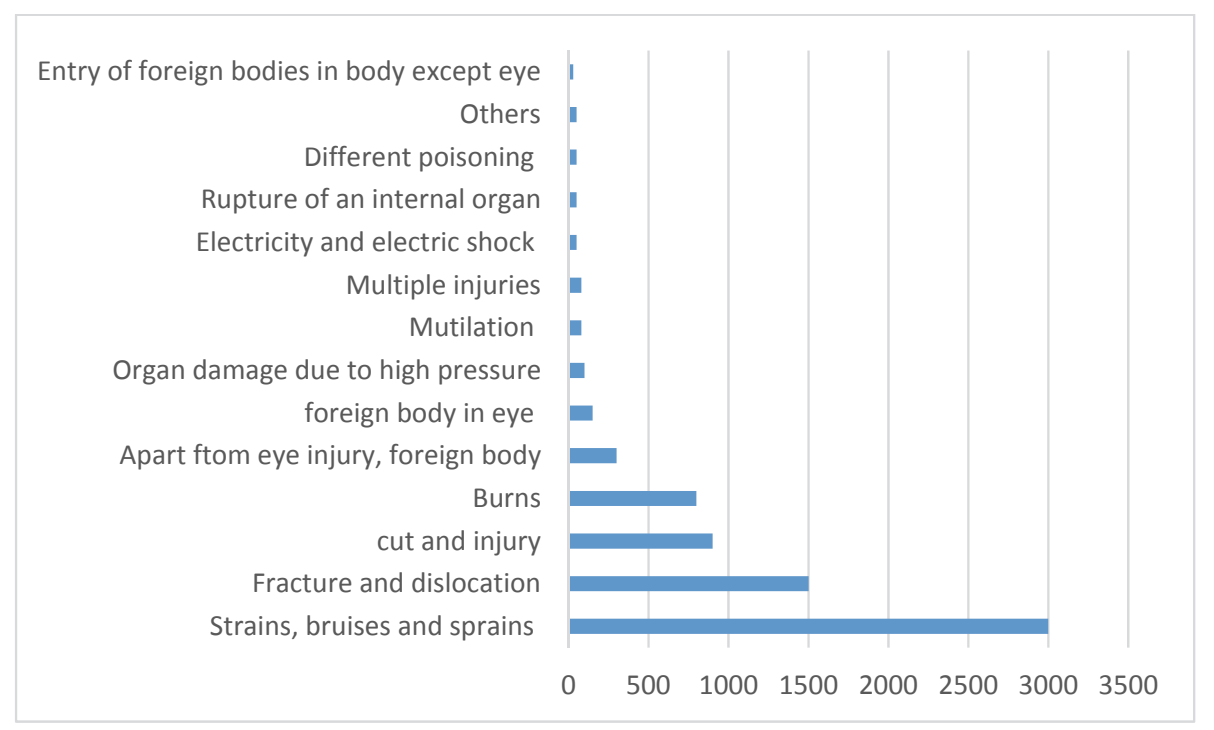

Fig. 1. Distribution of work related accidents in Iran industries

Accident may have serious influences on lives and health of employees and probably causes serious damages to the manufacturing facilities. However, safety evaluations help us avoid the accidents and/or reduce the casualties and damages as much as possible. Nowadays, safety management is mostly about preventing the accident from happening, rather than reacting when it happens. Prevention can require information for employees about place of accident and about how this accidents may happen (Larsson $\&$ Field, 2002). Calculate of lost workdays can be useful to measure the safety of mine, this measurement can feedback some information such as self-organized protection.

Injuries and deaths in mines cause expenses, and according to Andreoni (1983) are divided to firsthand and second-hand expenses. First-hand expenses consists of treatment costs, disability costs, and so forth. Second-hand expenses includes expenses due to lack of production, time loss during serious injuries and first-aid, and the expenses due to machinery failure when someone is trapped. The cost of accidents in the mining industry is approximated to be as much as 454 million euros in EU15 Member States (Eurostat, 2004).

One other factor affecting mines' performance is the company's sales revenue that has an obvious effect on the mine's performance. Every minute or every hour that the company stops the production, will cause financial losses that are very difficult to compensate. The value of lost workdays are effective extend to estimate performance of safety in mine, also this factor can show personnel protection instruments, and ease of accessibility of first aid equipment. Therefore, the wasted work days caused by the absence of the operator or the machinery failure can be effective on the company's performance. Also, machinery failure will cause repairing costs. As an aforementioned, the quantity of the injured is very important to the company's performance, as injuries not only will cause the production to stop, but also will cause additional expenses such as treatment costs, and expenses caused by lack of man power. There are some factors that can help companies recognize their injuries measurement in their workplace. 
Accident frequency rate (AFR) is an indicator of the quantity of the accidents happening in a specified period of time. It can help companies reduce the accidents to a minimum level. These accidents are classified by the Health and Safety Executive. Regarding Karmis (2001), benefits of using AFR are: (1) It is good for self-comparison to analyze our system. (2) It is well accepted. Near miss (NA) is another useful indicator for companies to realize their injuries, it is based on the accidents that may lead to injuries, and it can prevent them from happening near misses present effective learning opportunities as events that lead to no injuries (Aspden et al., 2004; Barach \& Small, 2000). In safety science, near misses are known as forerunner to accidents and they are used to prevent accidents and injuries (Bird \& Germain, 1996).

Another indicator that we used in this paper is injury severity score. Injury severity scores (ISS) were defined by Baker et al. (1974) for the first time in the literature. ISS indicates the severity of the injury in different parts of the body, and is calculated by a formula which is presented in that paper. Based on injury severity score, information such as Time Spent in Hospital, surgeries, Expansion of permanent disability can be identified (Bull, 1975). All these three factors can help companies measure their injuries and even assign tasks to prevent accidents and injuries in their workplaces. After reviewing a literature of this field and discussing with professionals, we can figure out that mining industry plays an important role in economy and it is responsible for supply of raw materials for many factories. Thus, improving the performance of the mines is a priority, safety and health issues are important factors in mine's performance, and can affect the economy and the safety of the mine workers.

The rest of the paper is organized as follows: A brief literature review is provided in section 2. Section 3 describes methodologies utilized in this paper. Section 4 is dedicated to numerical results. Finally conclusion remarks are provided in section 5.

\section{Literature review}

According to previous statistics in mine's accident, there are many works related to accidents in mines since the beginning of last century (Marovelli, 1981; Ramani \& Mutmansky, 1999). Evaluation of safety factors are important in many industries. Because of high-risk operations, evaluation of safety in mine could be useful and in this regard several studies have been accomplished. Accidents and dangers happen in mines are very complicated and many factors could contribute to initiate this event (Sari et al., 2004). A fuzzy rule-based model were proposed by Gurcanli and Mungen (2009) to evaluate the risks that could happen in construction sites and they assessed the safety with uncertain data. By this method, previous statistic data, and experts' judgment, statistic data of present safety level can be combined. Combining these data and the subjective judgment of safety experts, this paper derives three parameters namely the accident likelihood, current safety level and accident severity and they are utilized as input parameters for the fuzzy rule-based system.

Coleman and Kerkering (2007) evaluated safety in coal mine by statistical analysis. The first objective of this study examined the distributions and summary statistics of all injuries reported to the Mine Safety and Health Administration from 1983 to 2004. Over the period studied, there were 31,515,368 lost workdays associated with mining injuries, for an equivalent of 5,700 person-year lost annually. The second objective addressed the problem of comparing safety program performance in mines for situations where denominator data were lacking. Mahdevari et al. (2014) proposed a methodology based on fuzzy TOPSIS to assess the risks associated with human health in order to manage control measures and support decision making, which could provide the right balance between different concerns, such as safety and costs. For this purpose, information collected from three hazardous coal mines namely Hashouni, Hojedk and Babnizu located at the Kerman coal deposit, Iran, were used to manage the risks affecting the health and safety of their miners. Altogether 86 hazards were identified and classified under eight categories: geotechnical, geochemical, electrical, mechanical, chemical, environmental, personal, and social, cultural and managerial risks. Kniesner and Leeth (2004) used coal mine 
production, injuries and safety examinations data to test cost-effectiveness of min's safety and relation between mine safety and mine inspection were estimated by sophisticated regression model.

Mital et al. (2000) used lost day and injury severity in different parts of body as indicators to evaluate the safety of mine. They applied labor statistics reports to achieve their objects. Ciarapica and Giacchetta (2009) considered occupational injuries and assessed them by neuro-fuzzy network. To achieve their goals, according to the trend in injury, they used injury data of Italian regions to develop the systematization schemes. Hermans et al. (2008) utilized factor analysis, analytic hierarchy process (AHP) and DEA to evaluate safety performance in road accidents. Abbaspour et al. (2009) determined efficiency of safety and health in oil and gas contractor with DEA approach. Hermans et al. (2009) assessed different risk aspects of safety in road system by using DEA and proposing a benchmarking of road safety. As this paper data set contains 21 European countries for which a separate, best possible model was constructed, a number of country-specific policy actions can be recommended.

Kutlu and Ekmekcioglu (2012) applied fuzzy TOPSIS integrated with fuzzy analytical hierarchy process to present fuzzy Failure Mode and Effects Analysis (FMEA) for evaluation of the risk factors of each potential failure mode in linguistic variables. For each failure modes, three risk factors including severity (S), occurrence (O), and detectability (D) were evaluated and their multiplication derives the risk priority number (RPN). However, there were many shortcomings of this classical crisp RPN calculations. This study introduced a fuzzy hybrid approach that allows experts to use linguistic variables for determining severity, occurrence, and detectability for PFMEA by applying fuzzy 'technique for order preference by similarity to ideal solution' (TOPSIS) and fuzzy analytical hierarchy process (FAHP).

There are several traditional risk management tools which are widely used in mining industries, like preliminary hazards analysis (PHA) and fault modes and effects analysis (FMEA) (Kecojevic et al., 2007). They could be used combined with binary matrices (BM), consequence analysis (CA), etc. Traditional FMEA evaluates hazards by using the risk priority number (RPN), which is a combination parameter of the risk factors occurrence $(\mathrm{O})$, severity of the event $(\mathrm{S})$ and the probability of detection before the risk (D). However, there are some limitations and problems within the FMEA method, like $\mathrm{O}, \mathrm{S}$ and D, and the RPN method has some weakness in term of accuracy such as small variation in a sub-factor may cause significantly different results (Liu et al., 2015; Bozdag et al., 2015). To deal with this weakness, many studies tried to modify the FMEA method. For example, Liu et al. (2015) combined FMEA with multiple criteria decision making (MCDM) methods and Chen and Wu (2013) and Zahiri et al. (2016) modified the FMEA by applying analytic hierarchy process (AHP) method.

Sarkar and Bhattacharya (2003) evaluated the safety performance of mines based on value added, effectiveness and profitability based on DEA. Shokouhi et al. (2010) performed Robust DEA by considering interval inputs and outputs and objective of this study was to maximize the efficiency by considering extra constraint. They used Monte-Carlo simulation for achieving the best gamma value that has the best efficiency. Also, Shokouhi et al. (2014) applied MRDEA by using robust optimization approach with regard to the process of changing the parameter value to their maximum value, an empirical distribution of internal efficiency gains for the case is achieved. This study showed that rank of each DMU should not calculate with efficiency of upper and lower bound of each DMU. In this study, Monte-Carlo simulation method was used for calculating the best gamma value with the best efficiency and the result showed that this approach is less complicated than RDEA. One year later, a new model for DEA with interval inputs and outputs was proposed by Shokouhi (2015). This paper considered a protected layer for each inputs and outputs to protect them by this layers. This model used this layers for calculating the efficiency of each DMU and maximize sum of this efficiency altogether.

Sadjadi and Omrani (2010) evaluated performance of Telecommunications Company in Iran with uncertain data. In this study, they applied BRDEA for evaluated efficiency of different units to develop 
the efficient frontier to real frontier by bootstrapped. In this study, unites of 23 provinces of telecommunication of Iran were investigated. Number of employers and money of each unites were considered as inputs and the number of fixed-line and mobile subscribers were supposed as an output in the study. Kalantary and Adel Azar (2014) assessed the performance of Tehran hospitals by using Sadjadi and Omrani's (2010) model. In this study, 23 hospital of Tehran were evaluated and number of doctors, nurses and number of beds were considered as inputs and number of surgeries and number of refer patients who are not admitted and number of patients who admitted and number of beds which is full were considered as outputs. Mardania and Salarpour (2015) assessed an ability of 23 provinces for producing potatoes, and inputs for this study were cost of human power, cost of renting land, renting facilities, cost of irrigation, fertilization, pesticide. The harvested potato was considered as an output. In this study, they used IDEA and RDEA, because of the difference between the inputs and the outputs in different DMUs and the experimental results were achieved by Monte Carlo simulation.

\section{Table 1}

\section{Comparison of researches in the literature}

\begin{tabular}{|c|c|c|c|}
\hline Paper Name & objective & Method & Result \\
\hline $\begin{array}{l}\text { Gurcanli and } \\
\text { Mungen (2009) }\end{array}$ & $\begin{array}{l}\text { Proposed a method for assessment of the risks } \\
\text { that workers expose to at construction sites. }\end{array}$ & $\begin{array}{l}\text { Fuzzy rule- } \\
\text { based }\end{array}$ & $\begin{array}{l}\text { Derived three parameters namely the accident likelihood, current safety level } \\
\text { and accident severity and they were utilized as input. The method was then } \\
\text { implemented on a tunneling construction site and risk level for all types of ac- } \\
\text { cidents was derived. }\end{array}$ \\
\hline $\begin{array}{l}\text { Coleman and } \\
\text { Kerkering } \\
(2007)\end{array}$ & $\begin{array}{l}\text { This study examined the distributions and sum- } \\
\text { mary statistics of all injuries reported to the Mine } \\
\text { Safety and Health. It also addressed the problem } \\
\text { of comparing safety program performance in } \\
\text { mines. }\end{array}$ & $\begin{array}{l}\text { beta distribu- } \\
\text { tion }\end{array}$ & $\begin{array}{l}\text { The probability of an injury having } 10 \text { or more lost workdays was } 0.52 \text { for coal } \\
\text { mine cases versus } 0.35 \text { for metal/nonmetal mine cases. }\end{array}$ \\
\hline $\begin{array}{l}\text { Satar Mahdevari } \\
\text { et al. (2014) }\end{array}$ & $\begin{array}{l}\text { Assessed the risks associated with human health } \\
\text { in order to manage control measures and support } \\
\text { decision making. }\end{array}$ & $\begin{array}{l}\text { Fuzzy TOP- } \\
\text { SIS }\end{array}$ & $\begin{array}{l}\text { Information collected from three hazardous coal mines namely Hashouni, Ho- } \\
\text { jedk and Babnizu located at the Kerman coal deposit, Iran, were used to manage } \\
\text { the risks affecting the health and safety of their miners. }\end{array}$ \\
\hline $\begin{array}{l}\text { Kniesner and } \\
\text { Leeth (2004) }\end{array}$ & $\begin{array}{l}\text { Using recently assembled data from the Mine } \\
\text { Safety and Health Administration (MSHA) this } \\
\text { paper shed new light on the regulatory approach } \\
\text { to workplace safety. }\end{array}$ & Data Mining & $\begin{array}{l}\text { Most favorable to the agency, MSHA is not currently cost effective. Almost } \\
700,000 \text { life years could be gained for typical miners if a quarter of MSHA's } \\
\text { enforcement budget were reallocated to other programs. }\end{array}$ \\
\hline $\begin{array}{l}\text { Mital et al. } \\
(2000)\end{array}$ & $\begin{array}{l}\text { Focused on key overall nonfatal occupational in- } \\
\text { jury trends in the United States, back injuries, and } \\
\text { injuries to the upper extremities. }\end{array}$ & $\begin{array}{l}\text { DEA(BCC } \\
\text { output-ori- } \\
\text { ented) }\end{array}$ & $\begin{array}{l}\text { The primary result of this work was to extract information from massive and } \\
\text { voluminous databases of the Bureau of Labor Statistics (BLS) and the National } \\
\text { Safety Council (NSC), and presented them in usable form to ergonomics re- } \\
\text { searchers and practitioners. }\end{array}$ \\
\hline $\begin{array}{l}\text { Ciarapica and } \\
\text { Giacchetta } \\
(2009)\end{array}$ & $\begin{array}{l}\text { Assessed the risk of occupational injury, by con- } \\
\text { sidering the probability and consequences of in- } \\
\text { juries that may occur, and at identifying any gen- } \\
\text { eral factors which may affect the incidence of in- } \\
\text { juries. }\end{array}$ & $\begin{array}{l}\text { Neuro-fuzzy } \\
\text { techniques, } \\
\text { Data mining }\end{array}$ & $\begin{array}{l}\text { Real application of the flexibility and advantages of using the neuro-fuzzy net- } \\
\text { work, a typical soft computing tool, for an occupational injury study. }\end{array}$ \\
\hline $\begin{array}{l}\text { Hermans et al. } \\
(2008)\end{array}$ & $\begin{array}{l}\text { Focused on an essential steps in the construction } \\
\text { process of a composite road safety performance } \\
\text { indicator: the assignment of weights to the indi- } \\
\text { vidual indicators. In the composite indicator. }\end{array}$ & $\begin{array}{l}\text { Weighting } \\
\text { methods }\end{array}$ & $\begin{array}{l}\text { Only one country, Belgium, obtained the maximum score due to its very high } \\
\text { infrastructure value. Although all seven indicator domains were } \\
\text { considered very relevant for road safety, the visibility domain (and the daytime } \\
\text { running lights indicator) received zero weight. }\end{array}$ \\
\hline $\begin{array}{l}\text { Abbaspour et al. } \\
(2009)\end{array}$ & Evaluated different oil and gas contractors. & DEA & $\begin{array}{l}\text { Results of method showed that the main oil contractor was the most efficient } \\
\text { contractor among all contractor. }\end{array}$ \\
\hline $\begin{array}{l}\text { Hermans et al. } \\
(2009)\end{array}$ & $\begin{array}{l}\text { Road safety performance indicators (SPI) was } \\
\text { proposed as a useful instrument in comparing } \\
\text { countries on the performance of different risk as- } \\
\text { pects of their road safety system. }\end{array}$ & DEA & $\begin{array}{l}\text { Alcohol and drugs, speed, protective systems, vehicle, infrastructure and } \\
\text { trauma management were main performance indicators. For each country that } \\
\text { performs relatively poor, a particular country will be assigned as a useful } \\
\text { benchmark. }\end{array}$ \\
\hline $\begin{array}{l}\text { Kutlu and Ek- } \\
\text { mekcioglu } \\
(2012)\end{array}$ & $\begin{array}{l}\text { Evaluated the risk factors of each potential failure } \\
\text { mode in linguistic variables. }\end{array}$ & fuzzy TOPSIS & $\begin{array}{l}\text { This study introduced a fuzzy hybrid approach that allows experts to use lin- } \\
\text { guistic variables for determining S, O, and D for PFMEA by applying fuzzy } \\
\text { 'technique for order preference by similarity to ideal solution' (TOPSIS) and } \\
\text { fuzzy 'analytical hierarchy process' (AHP). }\end{array}$ \\
\hline Liu et al. (2015) & $\begin{array}{l}\text { The current FMEA determined the risk priorities } \\
\text { of failure modes by using risk priority numbers } \\
\text { (RPNs), which require the risk factors, occur- } \\
\text { rence (O), severity (S) and detection (D), to be } \\
\text { evaluated in crisp values. }\end{array}$ & $\begin{array}{l}\text { Fuzzy deci- } \\
\text { sion-making }\end{array}$ & $\begin{array}{l}\text { By comparing with the listed approaches, the results show that the proposed } \\
\text { method was a suitable and effective method for prioritization of failures in sys- } \\
\text { tem FMEA. }\end{array}$ \\
\hline $\begin{array}{l}\text { Chen and Wu } \\
\text { (2013) }\end{array}$ & Modified the FMEA & AHP & $\begin{array}{l}\text { Proposed method was a suitable and effective method for prioritization of fail- } \\
\text { ures in system FMEA. }\end{array}$ \\
\hline $\begin{array}{l}\text { Sarkar and } \\
\text { Bhattacharya } \\
\text { (2003) }\end{array}$ & Evaluated the safety performance of mines & DEA & $\begin{array}{l}\text { Evaluated the safety performance of mines based on value added, effectiveness } \\
\text { and profitability and value added was the most efficient factor among factors. }\end{array}$ \\
\hline This study & $\begin{array}{l}\text { Evaluated the performance of mine by integrated } \\
\text { economic and safety factors }\end{array}$ & Robust DE & \\
\hline
\end{tabular}

The current study identifies factors that are affecting in mine industries by integrating economic and safety factors. Many previous studies in the field of mine's safety to assess and evaluate the mines safety have used different indicators, but using combination of safety and economic factors are not considered according to the best of our knowledge. To this end, this paper attempts to assess performance of a mine by safety and economic factors together by using Robust DEA. 


\section{Methodology}

In this study, for assessing and evaluating safety and economic dimensions, a straightforward and new framework was proposed. The details of framework's phases including 8 steps are illustrated in Fig. 1:

- Phase 1:

○ Identify effective factors influencing on mine's performance based on literature review,

$\circ$ A real safety and economic data has been collected from a mine.

- Phase 2:

- We perform economic and safety factors such as income, return on investment and value added as output and cost, injury, lost days, accident frequently rate, injury severity score as input in DEA and Robust DEA and common weight Robust DEA model.

- Phase 3:

- We apply result of models and compare them with each other.

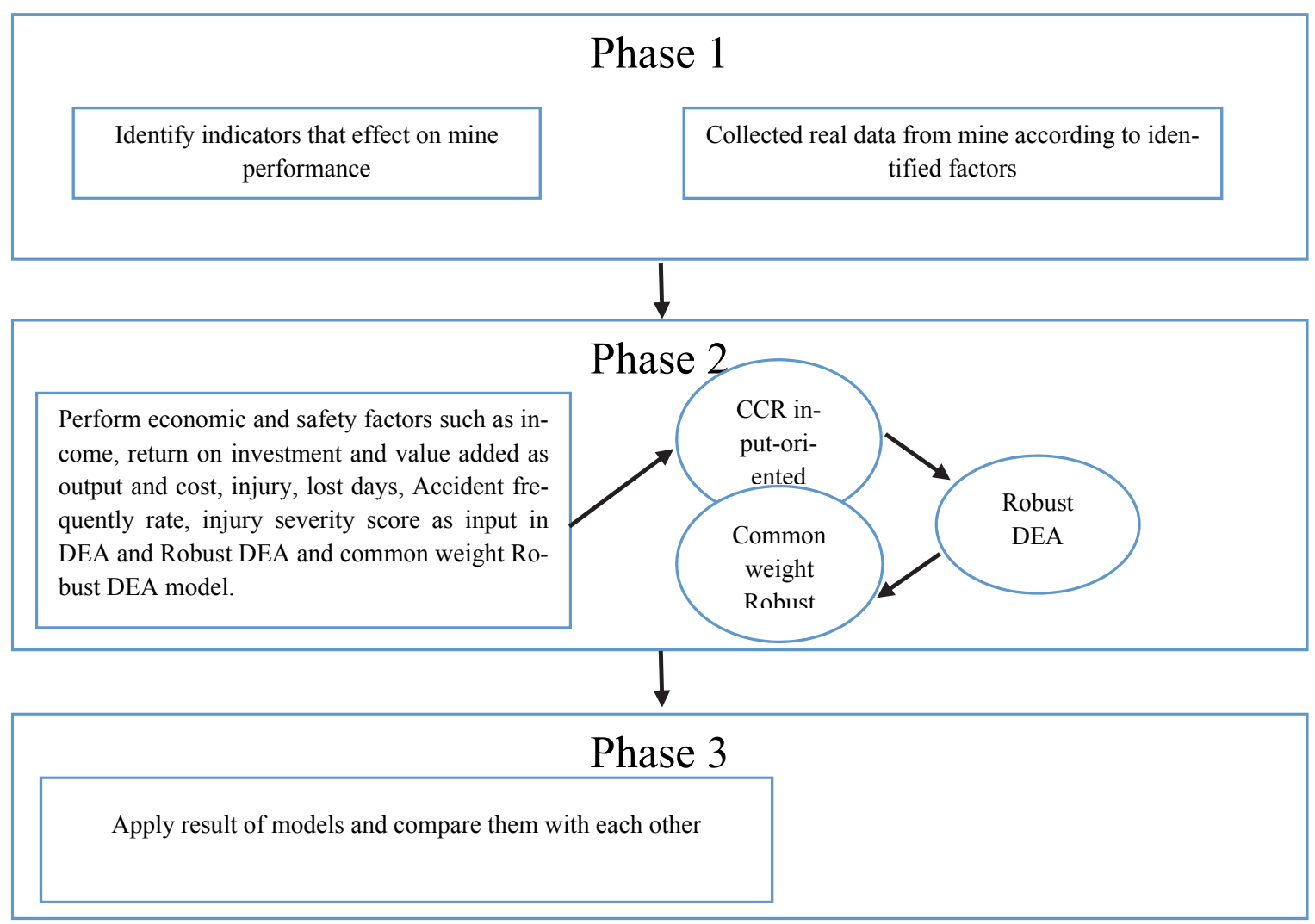

Fig. 1. Flowchart of the proposed framework.

\section{a. Data collection}

In this study, safeties and economics dimensions are used to evaluate performance of mines in north of Iran. Safety factors that are used to evaluate performance of mine industries are: accident frequency rate, injury severity score, near miss, injury.

Accident frequency rate: Number of accidents that happened in period of time in the company is calculated as follows,

$$
A F R=\frac{\text { No.of accidents happens in year } * 100000}{\text { No.of works hour in year } * \text { No. of workers }}
$$


Injury severity score: ISS is an indicator for assess level of injury that happened in industries and it is divided in 6 important parts of body and injure of this part of body is determined as an Abbreviated Injury Scale (AIS) score which shows the severity of each injure in different parts of body and ISS can be scored from 0 to 75 . The following website can help to calculate ISS:

http://www.trauma.org/archive/scores/iss

Near miss: This indicator is defined as accidents that almost happen in industries and it could not be happened in other times. By this indicator companies can reduce the possibilities of their events.

Injury: This factor is defined as accidents that cause dangerous events on different parts of body.

After that, we consider economic factors that influence on mine industries which are: Income, Cost, Return on Investment, Lost days and Value added.

\section{b. DEA methods}

DEA is used for the proposed model of this paper. The first DEA model was established for solving a linear programing to find technical efficiency (Farrell, 1957). DEA compares different inputs and outputs based on decision making units (DMUs) and identifies the best DMU, compared with the rest of DMUs. There are many researches using DEA in different studies for evaluating DMUs efficiency (Charnes et al., 1978; Azadeh et al., 2014).

DEA can merge many data that it takes into an efficiency score and it is the most advantage of DEA from other data fusion methods (i.e. Principal Component Analysis (PCA)). Unknown variance of efficiency scores is the disadvantage of DEA method (Kauppinen \& khajehzadeh, 2015). The main benefits of using DEA in this study are: efficient and inefficient modules are identifiable in this method and results of this model can help decision makers evaluate performance of their systems and making some improvement (Charnes et al., 1978). Even this model can consider input and output factors together and calculate efficiency scores (Serrano Cinca et al., 2006).

The number of studies that used DEA in their papers is growing and it is obvious that DEA method has become popular compared with traditional regression modelling (Kauppinen \& Khajehzadeh, 2015). DEA has been used in many different places. The basic example for usage of DEA is in medical facilities, where DEA can be used to find the most efficient facilities and compare them with each other (Kauppinen et al., 2008). In addition, we can use DEA to compare different factories that produce the same product (Kauppinen \& Khajehzadeh, 2015). In DEA method, efficiency of each DMU can be established by maximum weight distribution of inputs to outputs weights variables as shown in model (1). DEA model should be run $n$ times for all $k$ DMUs to achieve the comparative efficiency of all DMUs.

$$
\begin{array}{ll}
\max & \theta_{0}=\frac{\sum_{r=1}^{s} u_{r} y_{r 0}}{\sum_{i=0}^{m} v_{i} x_{i 0}} \\
\text { s.t. } & \frac{\sum_{r=s}^{s} u_{r} y_{r 0}}{\sum_{i=1}^{m} v_{i} x_{i 0}} \leq 1, \quad z=1, \ldots . k \\
u_{r} v_{i} \geq 0, \quad i=1, \ldots, m, \quad r=1, \ldots, s
\end{array}
$$

In model (1), there are $q$ inputs and $s$ outputs and variable of $v_{i}$ and $u_{r}$ is defined as the weights of input $i$ and output $r$, respectively. Also, efficiency of $\mathrm{DMU}_{0}$ shows as $\theta_{0}$. The model 1 is non-linear model and the transformed linear programming (LP) of model is:

$$
\max \theta_{0}=\sum_{r=1}^{s} u_{r} y_{r 0}
$$




$$
\begin{aligned}
& \text { s.t. } \sum_{r=1}^{s} u_{r} y_{r 0}-\sum_{i=1}^{q} v_{i} x_{i 0} \leq 0, \quad z=1, \ldots, k \\
& \sum_{i=1}^{m} v_{i} x_{i 0}=1 \\
& u_{r}, v_{i} \geq \varepsilon, \quad i=1, \ldots, m, \quad r=1, \ldots, s
\end{aligned}
$$

Three models used for this study are Banker et al. (CCR) model (Charnes et al., 1978), Charnes and Cooper (BCC) model (Banker et al., 1984), and additive model (Charnes \& Neralić, 1990). These DEA models are input and output oriented and Russell's model is improvement model of basic DEA defined as compound of input and output. (See FaÈre et al. (1985), pp. 160, 161).

- $\quad$ CCR model

CCR input oriented model evaluates DMU's efficiency by minimizing the inputs while outputs are as restriction. The model is as follow:

$$
\begin{aligned}
& \min \quad \theta_{0} \\
& \text { s.t. } \quad \theta_{0} x_{i 0} \geq \sum_{z=1}^{k} \beta_{j} x_{i j}, \quad i=1, \ldots, q \\
& y_{r 0} \leq \sum_{z=1}^{k} \beta_{z} y_{r z}, \quad r=1, \ldots, s \\
& \beta_{z} \geq 0, \quad z=1, \ldots, n
\end{aligned}
$$

By maximizing the outputs as inputs in constraint, the output oriented model achieved and this model is shown in Eq. (4):

$$
\begin{aligned}
& \max \quad \theta_{0} \\
& \text { s.t. } \quad x_{i 0} \leq \sum_{z=1}^{k} \beta_{j} x_{i j}, \quad i=1, \ldots, q \\
& \theta_{0} y_{r 0} \geq \sum_{z=1}^{n} \beta_{z} y_{r z}, \quad r=1, \ldots, s \\
& \beta_{z} \geq 0, \quad z=1, \ldots, n
\end{aligned}
$$

- BCC model

BCC model has one more constraint than CCR model where this constraint is equal to the summation of $\lambda_{\mathrm{j}}$. The linear programming of output oriented of this model is formulated as follows,

$$
\begin{aligned}
& \max \quad \theta_{0} \\
& \text { s.t. } \quad x_{i 0} \leq \sum_{z=1}^{k} \beta_{z} x_{i z}, \quad i=1, \ldots, q \\
& \theta_{0} y_{r 0} \geq \sum_{z=1}^{k} \beta_{z} y_{r z}, \quad r=1, \ldots, s \\
& \sum_{z=1}^{k} \beta_{z}=1
\end{aligned}
$$


$\beta_{z} \geq 0, \quad z=1, \ldots, k$

The input oriented model of BCC is achieved just like the output oriented model by adding extensive constraint of $\mathrm{BCC}$ output oriented as follows:

$$
\begin{aligned}
& \min \quad \theta_{0} \\
& \text { s.t. } \quad \theta_{0} x_{i 0} \geq \sum_{z=1}^{k} \beta_{z} x_{i j}, \quad i=1, \ldots, q \\
& y_{r 0} \leq \sum_{z=1}^{k} \beta_{z} y_{r z}, \quad r=1, \ldots, s \\
& \sum_{z=1}^{k} \beta_{z}=1 \\
& \beta_{z} \geq 0, \quad z=1, \ldots, k \\
& \text { c. } \quad \text { Robust optimization }
\end{aligned}
$$

\section{c. Robust optimization}

In this section, a robust optimization approach as an alternative for the stochastic programming and sensitivity analysis, will be explained. In robust optimization, we ensure that a planning constraint is violated through a very low probability given by the decision/design vector. To present the robust modeling, consider the following LP problem:

$$
\begin{aligned}
& \text { Min } c^{\prime} x \\
& E x=d \\
& A x \geq b \\
& x \in X
\end{aligned}
$$

where, $c_{0}$ is the row vector of the corresponding costs, and $x$ is the column vector of variables. The constraints are separated into two parts: equality and inequality constraints. $E$ and $A$ are the coefficient matrices of the equality and inequality constraints, respectively. Also, $d$ and $b$ are the column vectors of right-hand side values of the equality and inequality constraints, respectively. It is assumed that the coefficients in $A$ are uncertain and $X$ is a polyhedron. In robust optimization technique, we consider a particular row $i(i=1, \ldots, m)$ of the matrix $A$ and $J_{i}$ represents the set of coefficients in the row $i$ that are subject to uncertainty. Assume that the true values $\tilde{a}_{i j}(\mathrm{j}-1 ; \ldots ; \mathrm{n})$ of uncertain data entries in $i$-th inequality constraint are obtained from the nominal values $a_{i j}$ of the entries by random perturbations:

$$
\tilde{a}_{i j}=\left(1+e_{i j} ¥_{i j}\right) a_{i j}=a_{i j}+¥_{i j} \hat{a}_{i j}
$$

where $e_{i j}>0$ is a given uncertainty level (percentage of perturbation) and $\hat{a}_{i j}$ measures the precision of the estimation. Also, $¥_{i j}\left(¥_{i j}=0\right.$ for $\left.j \notin J_{j}\right)$ is the scaled deviation from nominal value and has an unknown but symmetric distribution which takes values in the range of $[-1,1]$. Therefore, each entry $\tilde{a}_{i j} ; j \in J_{i}$ is modeled as a symmetric and bounded random variable which takes values in $\left(a_{i j}-\hat{a}_{i j} ; a_{i j}+\hat{a}_{i j}\right)$. Although the aggregated scaled deviation for constraint $i$ could take any value in the range of $\left[-n_{i}, n_{i}\right]$ but it is limited to $\sum_{j}^{n} ¥ i j \leqslant \Gamma_{i}$. Therefore, for each constraint $i$, a parameter $C_{i}$, not necessarily integer, is introduced taking values in the interval $\left[0, n_{i}\right]$ (Bertsimas and Sim, 2004). The role of the parameter $\Gamma_{i}$ is to adjust the robustness of the proposed method against the level of conservatism of the solution. $\Gamma_{i}$ is called the budget of uncertainty of constraint $i$. If $\Gamma_{i}=0$, there is no protection against any uncertainty. If $\Gamma_{i}=n_{i}$, the $\mathrm{i}$-th constraint of the problem is fully protected against uncertainty. Finally, if $\Gamma_{i} \in\left(0, n_{i}\right)$, the decision maker makes a trade-off between the protection level of the constraint and the degree of conservatism for the solution. The robust formulation of the model (9) based on Bertsimas and Sim (2004) is as follows: 
$\min c_{x}$

$E x=d$

$\mathrm{a}_{i} x-\Gamma_{i} p_{i}-\sum_{j \in J_{j}} q_{i j} \geq b_{i}, \forall i$

$p_{i}+q_{i j} \geq e a_{i j} y_{j}, \forall i, j$

$-y_{j} \leq x_{j} \leq y_{j}, \forall j$

$p_{i}, q_{i j}, y_{j} \geq 0$

$\mathrm{x} \in \mathrm{X}$

The common weight robust optimization for calculating common weight of each factors is as follow:

$$
\begin{aligned}
& \min \sum_{j=1}^{n}(q+z) \\
& \sum_{r=1}^{s} u_{r} y_{r j}+\sum_{i=1}^{m} \theta_{j} v_{i} x_{i j}+p_{j} \gamma_{j}+\sum_{j \in J} q_{r j}+\sum_{j \in J} q_{i j} \leq 0 \quad j=1, \ldots, n \\
& \sum_{r=1}^{s} u_{r} y_{r j}+\sum_{i=1}^{m} \delta_{j} v_{i} x_{i j}+\mathrm{q}+\mathrm{z}=0 \quad j=1, \ldots, n \\
& \sum_{r=1}^{s} u_{r}+\sum_{i=1}^{m} v_{i}=1 j=1, \ldots, n \\
& p_{i}+q_{i j} \geq e x_{i j} z_{j}, \forall i, j \\
& p_{i}+q_{r j} \geq e y_{r j} z_{j}, \forall r, j \\
& -z_{r} \leq u_{r} \leq z_{r}, \forall r \\
& -z_{i} \leq v_{i} \leq z_{i}, \forall i \\
& p_{j}, q_{i j}, q_{r j}, z_{i}, z_{r} \geq 0
\end{aligned}
$$

The first constraint in the model (10) is used for modeling uncertainty in input and output data and the second one is applied for calculating the common weights in RDEA model. In latter constraint, the deviations from ideal value of $f_{j}$ (zero) are shown by $q+z$. In other words, the value of $f_{j}$ must be equal to zero and any deviation from zero must be minimized. The objective function of the model (10) minimizes the sum of deviations for all DMUs. Briefly, the following steps are implemented to find out common weights in robust DEA:

1. Solve the models DEA and Robust DEA and calculate the efficiency $(\theta)$ and robust efficiency $(\delta)$ scores for all DMUs

2. Consider $\theta$ and $\delta$ for DMU $j$, solve the model (10) and obtain the common weights $(v, u)$

3. Calculate the final robust common weights efficiency scores by using Eq. (11)

$$
\varphi_{j}=\frac{\sum_{r=1}^{s} u_{r} y_{r j}}{\sum_{i=1}^{m} v_{i} x_{i j}}
$$

\section{Case study}

To find factors affecting on mine's performance, a mine in the north of Iran (exactly in Mazandaran province and in Neka city) with 56 different sites of extract is investigated. This mine has 75 employees and its revenue is about a million dollar in a month.

Extraction of this mine are different kinds of sands and Gravel. This mine contacts with many construction companies and other companies who need this production such as: Construction Companies, company sealants and other related companies. It has one central site that machines which coverts raw 
sand to different kinds of sands and sales department located in this site and all business works are performed in this site.

\section{Results}

We have used DEA, RDEA and CWRDEA to assess the performance of 56 different sites of a mine in north of Iran. After gathering the necessary data from sources the models are applied.

\section{a. DEA result}

The results of DEA for 56 sites of a mine are shown in Table 2. In this study, we have used CCR input oriented model for this case. Moreover, the results show that many of these sites were efficient. As a fact this result cannot be realistic, because of that in this study we have added an uncertainty factor in order to find better results.

\section{b. RDEA result}

The results of the RDEA model are shown in Table 2. Regarding to the existence of a few sources of the uncertain data (number of inputs and outputs) in order to ensure full protection, it is necessary that $\boldsymbol{\Gamma}$ to be set equal to 4 for all constraints. The value of $\boldsymbol{\Gamma}=4$ implies that the system is protected against $100 \%$ of the uncertain parameters taking their worst-case value. Also, the perturbations $e_{i}$ are set to 5\% for all uncertain data. According to the RDEA model, minimum, maximum and mean of efficiency scores for Iranian provincial gas companies in 2008 are $0.4927,0.9981$ and 0.7828 , respectively.

\section{c. CWRDEA result}

Now, the CWRDEA model is applied to a cross-section of 56 sites of sand mine company and efficiency measures are calculated for each unit of the given data set. We have assumed that the measurement errors in the mine' data could be up to $5 \%$ (of the measured values). In addition, management center wanted to compare and rank the companies with common weights for inputs and outputs. The results of CWRDEA model for this mine are shown in Table 2. As shown, the highest and the lowest scores the efficiency scores change from 0.4927 and 0.9981 to 0.4894 and 0.9857 . The mean overall technical efficiency score of sand mine company is 0.7746 . Also, the results of common weights are shown in Table 2 these common weights are calculated for $\Gamma=4$.

\section{Conclusion}

In this paper, a common weight robust DEA was performed in order to calculate the performance of different sites of sand mine in north of Iran and rank them to identify the most efficient site among 56 sites which are available in this mine. CCR model gives efficiency without uncertainty, but in real situation, data is not absolutely fixed and a level of uncertainty is available. Because of this reason, in this study we used common weight robust DEA for: (1) by considering uncertainty in this study and (2) by considering input and output together. The results showed that using common weight robust DEA model could be more efficient than other DEA model without uncertainty and we could identify the most efficient DMUs in real situation. For future studies, we recommend to apply the models presented in this study to other industrial and economical centers such as shopping centers, hospitals and industrial plants. 
Table 2

Efficiency of different DMU in different DEA model

\begin{tabular}{|c|c|c|c|c|c|c|}
\hline DMU & DEA & Rank & RDEA & Rank & CWRDEA & Rank \\
\hline site01 & 1 & 1 & 0.9274 & 16 & 0.9046 & 17 \\
\hline site 02 & 1 & 1 & 0.9710 & 7 & 0.9705 & 6 \\
\hline site 03 & 0.5972 & 52 & 0.5507 & 51 & 0.5469 & 50 \\
\hline site04 & 0.6427 & 46 & 0.5930 & 46 & 0.5786 & 46 \\
\hline site 05 & 0.6018 & 51 & 0.5348 & 52 & 0.5348 & 52 \\
\hline site06 & 0.5378 & 54 & 0.5104 & 54 & 0.5104 & 54 \\
\hline site 07 & 1 & 1 & 0.9176 & 17 & 0.9134 & 16 \\
\hline site 08 & 0.9630 & 21 & 0.9476 & 12 & 0.9390 & 11 \\
\hline site09 & 1 & 1 & 0.8994 & 19 & 0.8925 & 21 \\
\hline site10 & 1 & 1 & 0.9174 & 18 & 0.8951 & 18 \\
\hline site11 & 1 & 1 & 0.9384 & 13 & 0.9374 & 12 \\
\hline site12 & 1 & 1 & 0.9862 & 3 & 0.9789 & 4 \\
\hline site 13 & 0.9412 & 23 & 0.8979 & 20 & 0.8928 & 20 \\
\hline site14 & 1 & 1 & 0.9638 & 8 & 0.9501 & 9 \\
\hline site 15 & 0.9865 & 19 & 0.9357 & 14 & 0.9346 & 13 \\
\hline site16 & 0.5878 & 53 & 0.5725 & 47 & 0.5522 & 49 \\
\hline site17 & 0.7195 & 39 & 0.6720 & 38 & 0.6615 & 38 \\
\hline site18 & 0.6380 & 47 & 0.5679 & 48 & 0.5679 & 47 \\
\hline site19 & 1 & 1 & 0.9581 & 10 & 0.9492 & 10 \\
\hline site20 & 0.9434 & 22 & 0.8792 & 24 & 0.8698 & 23 \\
\hline site21 & 0.5185 & 56 & 0.4927 & 56 & 0.4894 & 56 \\
\hline site22 & 0.7377 & 37 & 0.6527 & 39 & 0.6454 & 40 \\
\hline site23 & 0.9688 & 20 & 0.8248 & 26 & 0.8069 & 27 \\
\hline site24 & 1 & 1 & 0.8932 & 21 & 0.8931 & 19 \\
\hline site 25 & 0.6357 & 48 & 0.6247 & 44 & 0.6143 & 44 \\
\hline site26 & 0.7429 & 36 & 0.5563 & 50 & 0.5445 & 51 \\
\hline site 27 & 0.8126 & 33 & 0.7870 & 32 & 0.7862 & 31 \\
\hline site28 & 1 & 1 & 0.9346 & 15 & 0.9236 & 15 \\
\hline site29 & 0.6024 & 50 & 0.5640 & 49 & 0.5640 & 48 \\
\hline site 30 & 0.6779 & 41 & 0.5299 & 53 & 0.5294 & 53 \\
\hline site31 & 0.7641 & 35 & 0.6342 & 41 & 0.6123 & 45 \\
\hline site32 & 0.8691 & 27 & 0.7816 & 34 & 0.7760 & 32 \\
\hline site33 & 0.7799 & 34 & 0.7103 & 36 & 0.7069 & 36 \\
\hline site34 & 0.8577 & 30 & 0.7849 & 33 & 0.7684 & 34 \\
\hline site 35 & 0.6248 & 49 & 0.6153 & 45 & 0.6144 & 43 \\
\hline site36 & 0.5223 & 55 & 0.5034 & 55 & 0.4989 & 55 \\
\hline site37 & 0.8130 & 32 & 0.7908 & 31 & 0.7907 & 30 \\
\hline site 38 & 1 & 1 & 0.9981 & 1 & 0.9857 & 1 \\
\hline site39 & 1 & 1 & 0.9788 & 6 & 0.9588 & 7 \\
\hline site40 & 0.6521 & 43 & 0.6463 & 40 & 0.6463 & 39 \\
\hline site41 & 1 & 1 & 0.9794 & 5 & 0.9745 & 5 \\
\hline site 42 & 1 & 1 & 0.9970 & 2 & 0.9794 & 3 \\
\hline site43 & 0.7128 & 40 & 0.6957 & 37 & 0.6874 & 37 \\
\hline site44 & 0.9010 & 25 & 0.8902 & 22 & 0.8892 & 22 \\
\hline site45 & 1.0000 & 1 & 0.9609 & 9 & 0.9581 & 8 \\
\hline site 46 & 0.8624 & 28 & 0.8197 & 27 & 0.8310 & 26 \\
\hline site47 & 0.8168 & 31 & 0.8090 & 28 & 0.7943 & 28 \\
\hline site 48 & 0.6486 & 44 & 0.7930 & 30 & 0.7756 & 33 \\
\hline site49 & 1.0000 & 1 & 0.9523 & 11 & 0.9244 & 14 \\
\hline site 50 & 0.8590 & 29 & 0.8089 & 29 & 0.7931 & 29 \\
\hline site 51 & 0.6717 & 42 & 0.6300 & 43 & 0.6197 & 42 \\
\hline site52 & 0.9111 & 24 & 0.8876 & 23 & 0.8609 & 24 \\
\hline site 53 & 0.6467 & 45 & 0.6317 & 42 & 0.6277 & 41 \\
\hline site54 & 0.7375 & 38 & 0.7162 & 35 & 0.7086 & 35 \\
\hline site 55 & 0.8850 & 26 & 0.8354 & 25 & 0.8326 & 25 \\
\hline site56 & 1.0000 & 1 & 0.9841 & 4 & 0.9839 & 2 \\
\hline Mean & 0.8284 & & 0.7828 & & 0.7746 & \\
\hline
\end{tabular}

\section{References}

Abbaspour, K. C., Faramarzi, M., Ghasemi, S. S., \& Yang, H. (2009). Assessing the impact of climate change on water resources in Iran. Water resources research, 45(10).

Aspden, P., Corrigan, J. M., Wolcott, J., \& Erickson, S. M. (2003). Committee on Data Standards for Patient Safety." Patient Safety: Achieving a New Standard for Care." Washington, DC: Institute of Medicine. 
Azadeh, A., \& Salehi, V. (2014). Modeling and optimizing efficiency gap between managers and operators in integrated resilient systems: The case of a petrochemical plant. Process Safety and Environmental Protection, 92(6), 766-778.

Baker, S. P., o'Neill, B., Haddon Jr, W., \& Long, W. B. (1974). The injury severity score: a method for describing patients with multiple injuries and evaluating emergency care. Journal of Trauma and Acute Care Surgery, 14(3), 187-196.

Banker, R. D., Charnes, A., \& Cooper, W. W. (1984). Some models for estimating technical and scale inefficiencies in data envelopment analysis. Management science, 30(9), 1078-1092.

Barach, P., \& Small, S. D. (2000). Reporting and preventing medical mishaps: lessons from non-medical near miss reporting systems. British Medical Journal, 320(7237), 759.

Bertsimas, D., \& Sim, M. (2004). The price of robustness. Operations research, 52(1), 35-53.

Bird, F. E., \& Germain, G. L. (1996). Practical loss control leadership. Det Norske Veritas (USA).

Bozdag, E., Asan, U., Soyer, A., \& Serdarasan, S. (2015). Risk prioritization in Failure Mode and Effects Analysis using interval type-2 fuzzy sets. Expert Systems with Applications, 42(8), 40004015.

Bull, W. B. (1975). Landforms that do not tend toward a steady state. Theories of landform development, 6, 111.

Charnes, A., and L. Neralić. (1990). Sensitivity analysis of the additive model in data envelopment analysis. European Journal of Operational Research, 332-341.

Charnes, A., William W. Cooper, and Edwardo Rhodes. (1978). Measuring the efficiency of decision making units. European Journal of Operational Research, 429-444.

Ciarapica, F. F., and G. Giacchetta. (2009). Towards an international limit value for occupational trauma risk: industrial exposures associated with occupational trauma, permanent impairment and fatalities in a five-year national claims material. Safety Science, 39-46.

Chen, P. S., \& Wu, M. T. (2013). A modified failure mode and effects analysis method for supplier selection problems in the supply chain risk environment: A case study. Computers \& Industrial Engineering, 66(4), 634-642.

Coleman, P. J., and John C. Kerkering. (2007). Measuring mining safety with injury statistics: Lost workdays as indicators of risk. Journal of safety research, 523-533.

Färe, R., Grosskopf, S., \& Lovell, C. K. (2013). The measurement of efficiency of production (Vol. 6). Springer Science \& Business Media.

Farrell, M. J. (1957). The measurement of productive efficiency. Journal of the Royal Statistical Society. Series A (General), 120(3), 253-290.

Ghaffari, M. (2013). Safety and health in mining in IR Iran. List of contents.

Grayson, R. L., Harisha Kinilakodi, and Vladislav Kecojevic. (2009). Pilot sample risk analysis for underground coal mine fires and explosions using MSHA citation data. Safety Science, 1371-1378.

Gürcanli, G. E., and Ugur Müngen. (2009). An occupational safety risk analysis method at construction sites using fuzzy sets. International Journal of Industrial Ergonomics, 371-387.

Hermans, E., et al. (2009). Benchmarking road safety: lessons to learn from a data envelopment analysis. Accident Analysis and Prevention, 174-182.

Hermans, E., Filip Van den Bossche, and Geert Wets. (2008). Combining road safety information in a performance index. Accident Analysis and Prevention, 1337-1344.

Journal of Trauma and Acute Care Surgery, 187-196.

Kalantary, Z., \& Azar, A. (2014). A robust data envelopment analysis model for ranking: A case study of hospitals of Tehran. Data Envelopment Analysis and Performance Measurement, 21.

Karmis, M. (2001). Mine health and safety management. SME.

Kauppinen, T., \& Khajehzadeh, N. (2015). Sustainability in the exploration phase of mining: a Data Envelopment Analysis approach. IFAC-PapersOnLine, 48(17), 114-118.

Kauppinen, T., Lettenmeier, M., \& Lähteenoja, S. (2008). Data envelopment analysis as a tool for sustainable foodstuff consumption. Sustainable consumption and production: framework for action, 181. 
Kecojevic, V., Komljenovic, D., Groves, W., \& Radomsky, M. (2007). An analysis of equipment-related fatal accidents in US mining operations: 1995-2005. Safety Science, 45(8), 864-874.

Kniesner, T. J., and John D. Leeth. (2004). Data mining mining data: MSHA enforcement efforts, underground coal mine safety, and new health policy implications. Journal of Risk and Uncertainty, 83-111.

Kutlu, A. C., \& Ekmekçioğlu, M. (2012). Fuzzy failure modes and effects analysis by using fuzzy TOPSIS-based fuzzy AHP. Expert Systems with Applications, 39(1), 61-67.

Larsson, T. J., and Brian Field. (2002). The distribution of occupational injury risks in the Victorian construction industry. Safety Science, 439-456.

Liu, H. C., You, J. X., You, X. Y., \& Shan, M. M. (2015). A novel approach for failure mode and effects analysis using combination weighting and fuzzy VIKOR method. Applied Soft Computing, 28, 579-588.

Mahdevari, S., Shahriar, K., \& Esfahanipour, A. (2014). Human health and safety risks management in underground coal mines using fuzzy TOPSIS. Science of the Total Environment, 488, 85-99.

Mardani, M., \& Salarpour, M. (2015). Measuring technical efficiency of potato production in Iran using robust data envelopment analysis. Information Processing in Agriculture, 2(1), 6-14.

Marovelli, R. L. (1981). A comparison of American safety performance to other countries. Mining Congress Journal, 67. No. 8. 1920

Mital, A., Arunkumar Pennathur, and Achin Kansal. (2000). Nonfatal occupational injuries in the United States Part II-back injuries. International Journal of Industrial Ergonomics, 131-150.

Pham, V. H., Tran, T. N. L., Le, G. V., Movahed, M., Jiang, Y., Pham, N. H., ... and Takahashi, K. (2013). Asbestos and Asbestos-related Diseases in Vietnam: In reference to the International Labor Organization/World Health Organization National Asbestos Profile. Safety and health at work, 4(2), 117-121.

Ramani, R. V., and Jan M. Mutmansky. (1999). Mine health and safety at the turn of the millennium. Mining engineering, 25-30.

Sadjadi, S. J., \& Omrani, H. (2010). A bootstrapped robust data envelopment analysis model for efficiency estimating of telecommunication companies in Iran. Telecommunications Policy, 34(4), 221232.

Sari, M., et al. (2009). Stochastic modeling of accident risks associated with an underground coal mine in Turkey. Safety Science, 78-87.

Sarkar, S. K., \& Bhattacharya, A. K. (2003). Conservation of biodiversity of the coastal resources of Sundarbans, Northeast India: an integrated approach through environmental education. Marine pollution bulletin, 47(1), 260-264.

Serrano Cinca, C., Mar Molinero, C., \& Chaparro García, F. (1970). Behind DEA efficiency in financial institutions.

Shokouhi, A. H., Hatami-Marbini, A., Tavana, M., \& Saati, S. (2010). A robust optimization approach for imprecise data envelopment analysis. Computers \& Industrial Engineering, 59(3), 387-397.

Shokouhi, A. H., Shahriari, H., Agrell, P. J., \& Hatami-Marbini, A. (2014). Consistent and robust ranking in imprecise data envelopment analysis under perturbations of random subsets of data. OR spectrum, 36(1), 133-160.

Shokouhi, A. H., \& Shahriari, H. (2015). An Integrated Model with Conservative Levels to Evaluate the DMUs Efficiencies for Uncertain Data. Iranian Journal of Operations Research, 5(1), 29-46.

Zahiri, B., Tavakkoli-Moghaddam, R., \& Rezaei-Malek, M. (2016). An MCDA-DEA approach for mixed-model assembly line balancing problem under uncertainty. Journal of Intelligent \& Fuzzy Systems, 30(5), 2737-2748.

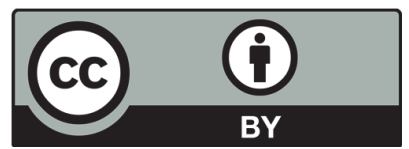

(C) 2017 by the authors; licensee Growing Science, Canada. This is an open access article distributed under the terms and conditions of the Creative Commons Attribution (CC-BY) license (http://creativecommons.org/licenses/by/4.0/). 